\title{
Osteomielitis pélvica en una paciente de 15 años. Presentación de un caso
}

\author{
Pelvic osteomyelitis in a 15-year-old girl. Case report
}

\author{
Dra. Tugce Tural Kara ${ }^{a}$, Dr. Halil Ozdemira ${ }^{a}$ Dr. Suat Fitoz ${ }^{b}$, Dr. Ergin Ciftci ${ }^{a}$ y Dr. Erdal Ince ${ }^{a}$
}

\begin{abstract}
RESUMEN
La osteomielitis pélvica es una infección poco frecuente, que suele afectar el ilion, el isquion, el pubis y el acetábulo. La radiografía de pelvis, la resonancia magnética de pelvis y el centellograma óseo son técnicas de diagnóstico porimágenes de mucha utilidad. Sin embargo, el diagnóstico debe confirmarse con la biopsia ósea de la lesión. A veces, el diagnóstico se retrasa debido a la localización profunda del foco infeccioso. Aquí presentamos el caso de una paciente de 15 años con dolor inguinal izquierdo, con diagnóstico de osteomielitis pélvica al mes de la manifestación de los síntomas iniciales. Recibió tratamiento antibiótico durante 8 semanas, con resultados satisfactorios. En conclusión, si bien la osteomielitis pélvica es una infección inusual en la infancia, debe considerarse como diagnóstico diferencial para el dolor en la ingle, la cadera, el muslo, el abdomen y la columna. Si se sospecha este diagnóstico, es necesario comenzar el tratamiento empírico de inmediato, porque es posible lograr resultados clínicos satisfactorios con el tratamiento eficaz.

Palabras clave: niños, dolor, osteomielitis pélvica aguda.
\end{abstract}

http:/ /dx.doi.org/10.5546/aap.2016.e370

\section{INTRODUCCIÓN}

La osteomielitis es una infección local del hueso frecuentemente causada por la diseminación de microorganismos hacia el hueso por vía hematógena. Entre otros factores predisponentes se incluyen la inoculación directa por traumatismos o procedimientos quirúrgicos, y la invasión local desde las partes blandas infectadas. Se calcula que la incidencia es de 1 cada 5000 a 7700 niños en los países desarrollados

a. Departamento de Enfermedades Infecciosas Pediátricas.

b. Departamento de Radiología Pediátrica.

Escuela de Medicina de Ankara Üniversitesi, Ankara, Turquía.

Correspondencia:

Dra. Tugce Tural Kara: tugcetural@hotmail.com

Financiamiento: Ninguno.

Conflicto de intereses: Ninguno.

Recibido: 29-2-2016

Aceptado: 21-4-2016 y de 1 cada 500 a 2300 niños en los países en vías de desarrollo. ${ }^{1}$ En los niños, la osteomielitis hematógena aguda suele afectar los huesos tubulares largos. ${ }^{2}$ Es más frecuente en los varones que en las niñas, y la mayoría de los niños con osteomielitis son menores de 5 años. ${ }^{3}$

Si bien la osteomielitis pélvica es poco frecuente en la infancia, es una enfermedad importante por las complicaciones que puede ocasionar si no se trata.

Los pacientes pueden ser hospitalizados con dolor en la cadera, muslo, abdomen o columna, y con dificultad para caminar. ${ }^{4}$ A veces, el diagnóstico se retrasa debido a la localización profunda del foco infeccioso. ${ }^{2}$ Además, no existen signos ni síntomas clínicos específicos que permitan descartar otras enfermedades infecciosas y ortopédicas. ${ }^{5}$

En este artículo presentamos el caso de una paciente con osteomielitis pélvica que recibió el diagnóstico al mes de la manifestación de los síntomas iniciales.

\section{PRESENTACIÓN DE UN CASO}

Una niña de 15 años ingresó al hospital con dolor inguinal izquierdo, sin antecedentes de fiebre o traumatismo. El dolor era constante en reposo y en movimiento, no respondía a los analgésicos y había comenzado hacía un mes atrás, aproximadamente. La paciente no presentaba dolor en el lado derecho de la cadera y la ingle; el dolor inguinal era más intenso del lado izquierdo y se irradiaba hacia la rodilla izquierda. El dolor no afectaba otras articulaciones. La paciente había perdido $5 \mathrm{~kg}$ en el último mes. En otros centros de atención, había recibido analgésicos y relajantes musculares, pero la paciente no respondía a los tratamientos contra el dolor.

Durante el examen físico, los signos vitales fueron los siguientes: temperatura corporal de $38,0^{\circ} \mathrm{C}$, frecuencia cardíaca de 108 latidos/min, presión arterial de 100/70 mmHg. No podía caminar sin apoyo ni pararse sobre el pie izquierdo. La amplitud de movimiento pasivo (flexión, abducción y rotación externa) estaba limitada en 
el lado izquierdo de la cadera. Los resultados de los análisis de laboratorio fueron los siguientes: hemoglobina de $11,6 \mathrm{~g} / \mathrm{dl}$, recuento de leucocitos de $11000 / \mathrm{mm}^{3}$ (neutrófilos $76 \%$, linfocitos $18 \%$ y monocitos $6 \%$ ), recuento de plaquetas de $571000 /$ $\mathrm{mm}^{3}$, velocidad de sedimentación globular (VSG) de $130 \mathrm{~mm} / \mathrm{h}$ y proteína C-reactiva (PCR) de $19,2 \mathrm{mg} / \mathrm{dl}$. No se hallaron signos patológicos en la radiografía pélvica (Figura 1). Se detectó edema muscular y de médula ósea del isquion con la resonancia magnética pélvica (RM) (Figura 2). Con estos resultados, se consideró el diagnóstico de osteomielitis y de un proceso infiltrativo maligno. Se realizó la aspiración de médula ósea, que fue normal. El centellograma óseo mostró captación patológica en la sínfisis púbica, la parte inferior de la articulación sacroilíaca izquierda, el isquion izquierdo y el acetábulo izquierdo (Figura 3). El diagnóstico de la paciente fue de osteomielitis, y se la trató con ceftriaxona por vía intravenosa. Durante el período de seguimiento, podía caminar con más comodidad y sentía menos dolor al mover el lado izquierdo de la cadera.

Al séptimo día de tratamiento antibiótico, sentía un dolor leve en el lado izquierdo de la cadera. La paciente tenía fiebre superior a $38{ }^{\circ} \mathrm{C}$ de forma discontinua, sin un foco determinado. Los reactantes de fase aguda seguían estando elevados (VSG: $130 \mathrm{~mm} / \mathrm{h}$ y PCR: 11,6 mg/dl). Para el diagnóstico diferencial de fiebre sin foco, se realizaron pruebas de detección de tuberculosis y enfermedades del

FiguRA 1. La imagen de radiografía pélvica está dentro de los límites normales

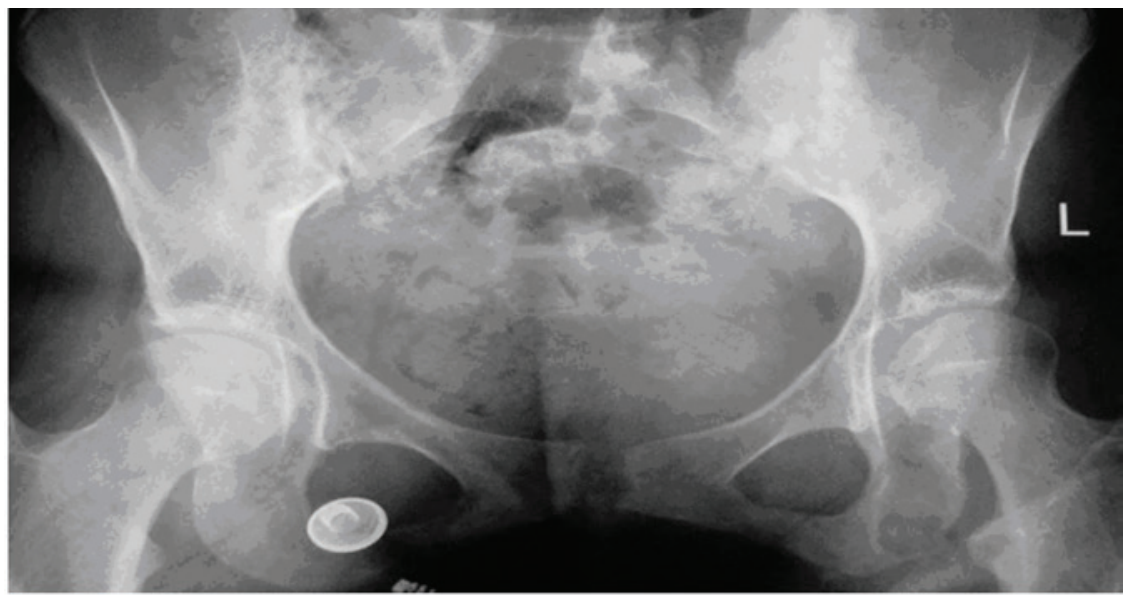

FIGURA 2. La imagen axial ponderada en T2 de la RM muestra cambios de señal hiperintensos en el isquion (flecha) y en los músculos (flecha curva)

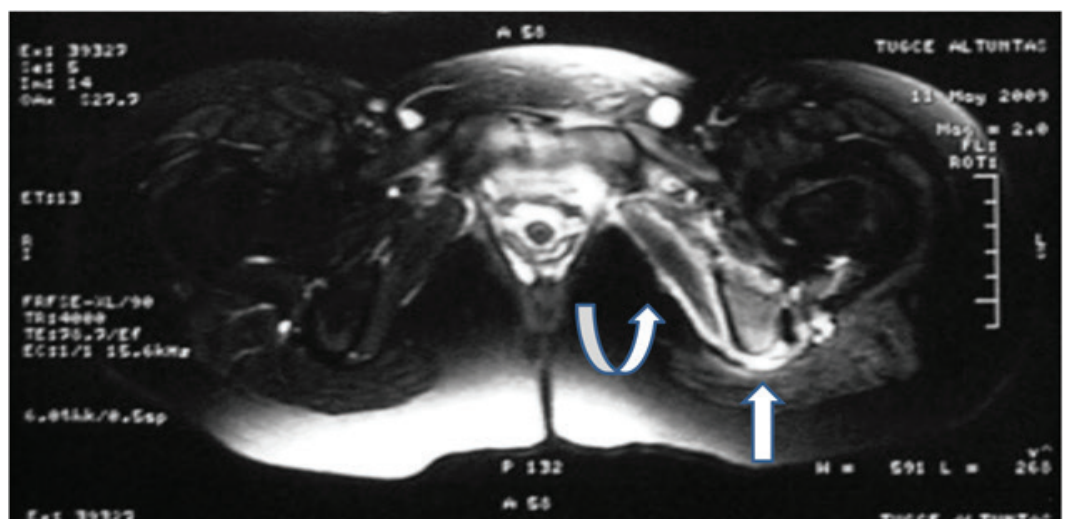


tejido conjuntivo (derivado proteico purificado: $2 \mathrm{~mm}$, título de antiestreptolisina O: $365 \mathrm{U} / 1$, factor reumatoideo: $8,44 \mathrm{mg} / \mathrm{dl}$, anticuerpos antinucleares: negativos, aglutinación para brucelosis: negativo), cuyos resultados fueron normales. Se detectó una leve expansión del lugar de la lesión en la RM pélvica de control. Con el fin de descartar cáncer u otro proceso infiltrativo óseo, se tomó una biopsia y se realizó el legrado de la lesión. El material de cultivo de la biopsia fue normal. La reacción en cadena de la polimerasa, los bacilos ácidorresistentes y el cultivo del material de la biopsia para detectar tuberculosis fueron negativos. En consecuencia, el diagnóstico de osteomielitis se confirmó con el examen anatomopatológico del material de biopsia. El tratamiento con ceftriaxona por vía intravenosa se prolongó durante 4 semanas. Se administró tratamiento con ciprofloxacina, y amoxicilina y clavulanato por vía oral durante 4 semanas después del alta. Al final del período de seguimiento de 10 meses, la paciente se había recuperado por completo, sin secuelas.

\section{DISCUSIÓN}

La osteomielitis hematógena del hueso pélvico es una infección pediátrica poco frecuente (del $6,3 \%$ al $20 \%$ ). ${ }^{2}$ Estudios anteriores han sugerido que el tiempo que transcurre entre el inicio de los síntomas y la hospitalización es prolongado, y que el diagnóstico a menudo se retrasa debido a la localización profunda del foco infeccioso. ${ }^{2,6} \mathrm{El}$ intervalo de edad de los niños con osteomielitis pélvica incluye edades más avanzadas que el de los niños con osteomielitis hematógena aguda. ${ }^{7}$ Si bien la osteomielitis pélvica es más frecuente en los varones, la proporción varones/mujeres $-(1,5 / 1)$ - es inferior que en la osteomielitis hematógena aguda. ${ }^{8}$ Algunos factores, como los procedimientos pélvicos, las infecciones urinarias, los traumatismos y la enfermedad de Crohn, pueden predisponer al desarrollo de osteomielitis. El hueso más comúnmente afectado es el ilion (38\%), debido a su abundante vascularización. Le siguen el isquion (19\%), el pubis (14\%) y el acetábulo (12\%). ${ }^{4}$ En este caso, la paciente recibió el diagnóstico de osteomielitis un mes después del inicio de los síntomas. Al revisar las publicaciones y comparar los resultados, se observó que las características de este caso, como la edad, el sexo y el lugar de compromiso óseo, son excepcionales.

Los antecedentes de traumatismo representan el $17 \%$ de los casos de osteomielitis pélvica, pero esta tasa es de, aproximadamente, el $40 \%$ en la osteomielitis de los huesos largos. Esto apoya la evidencia de que los huesos largos están más expuestos al traumatismo que el hueso pélvico. ${ }^{8}$ Los pacientes con osteomielitis pélvica pueden presentar diversos signos clínicos, lo que da lugar a diagnósticos erróneos o tardíos. El motivo principal de consulta es la fiebre y el dolor. En los niños, puede observarse pérdida de peso, anorexia, renguera o menor resistencia en las articulaciones de carga. ${ }^{2}$ Por lo general, el dolor afecta la cadera, los muslos o el abdomen.

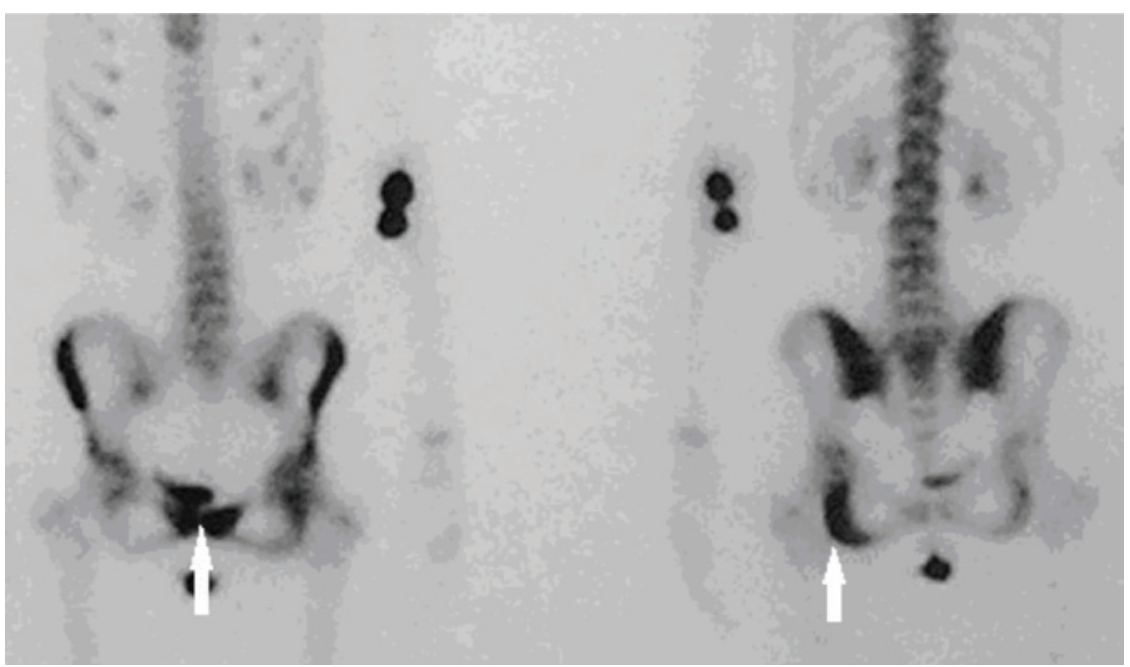


El hemocultivo o el cultivo del material aspirado de médula ósea pueden dilucidar el $50 \%$ de los microorganismos causales. El Staphylococcus aureus es el microorganismo causal más frecuente (90\%), lo que es similar a la osteomielitis hematógena aguda. ${ }^{4}$ En raras ocasiones, la osteomielitis pélvica es consecuencia de las bacterias del género Haemophilus influenzae, subespecies de Salmonella, Streptococcus del grupo A, Enterobacter cloacae y Pseudomonas aeruginosa. ${ }^{9}$ En el caso del género S. aureus, debe administrarse de inmediato un tratamiento empírico eficaz. Las cefalosporinas y la clindamicina por vía intravenosa son los agentes de tratamiento utilizados con mayor frecuencia. Si se aislan los microorganismos responsables, es necesario adecuar el tratamiento contra ellos. En los estadios iniciales de la enfermedad, es difícil detectar el compromiso óseo con la radiografía pélvica. La sensibilidad del centellograma óseo es superior. La RM pélvica es el mejor estudio de diagnóstico por imágenes, con un porcentaje del $82 \%$ al $100 \%$ de sensibilidad y del $75 \%$ al $96 \%$ de especificidad para el diagnóstico. ${ }^{10} \mathrm{El}$ pronóstico de la osteomielitis pélvica es muy bueno. La tasa de recuperación sin secuelas es superior al $95 \%$, pero disminuye con el diagnóstico tardío y el fracaso del tratamiento. Lamentablemente, puede haber casos de osteomielitis recurrente y deformaciones.

Los síntomas locales de inflamación, los resultados positivos de los hemocultivos o los cultivos del aspirado de médula ósea, la presencia de material purulento subperióstico y los cambios característicos en las radiografías o el centellograma apoyan el diagnóstico de osteomielitis hematógena. ${ }^{10}$ Nuestros resultados fueron suficientes para el diagnóstico de este caso.

En conclusión, la osteomielitis pélvica es poco frecuente en los niños, pero debe tenerse en cuenta para el diagnóstico diferencial en pacientes con dolor en la ingle y la cadera. En caso de sospecha clínica, el tratamiento empírico debe comenzar de inmediato. Si el tratamiento es eficaz, la frecuencia de las secuelas puede disminuir a tasas muy bajas.

\section{REFERENCIAS}

1. DartnellJ,RamachandranM,KatchburianM.Haematogenous acute and subacute paediatric osteomyelitis: a systematic review of the literature. J Bone Joint Surg Br 2012;94(5):58495.

2. Klein JD, Leach KA. Pediatric pelvic osteomyelitis. Clin Pediatr (Phila) 2007;46(9):787-90.

3. Gutierrez K. Bone and joint infections in children. Pediatr Clin North Am 2005;52(3):779-94.

4. Weber-Chrysochoou C,CortiN, GoetschelP,AltermattS, et al. Pelvic osteomyelitis: a diagnostic challenge in children. J Pediatr Surg 2007;42(3):553-7.

5. Kumar J, Ramachandran M, Little D, Zenios M. Pelvic osteomyelitis in children. J Pediatr Orthop B 2010;19(1):38-41.

6. Davidson D, Letts M, Khoshhal K. Pelvic osteomyelitis in children: a comparison of decades from 1980-1989 with 1990-2001. J Pediatr Orthop 2003;23(4):514-21.

7. Hammond PJ,MacnicolMF. Osteomyelitis of the pelvis and proximal femur: diagnostic difficulties. J Pediatr Orthop B 2001;10(2):113-9.

8. Zvulunov A, Gal N, Segev Z. Acute hematogenous osteomyelitis of the pelvis in childhood: Diagnostic clues and pitfalls. Pediatr Emerg Care 2003;19(1):29-31.

9. Akhras N, Blackwood A. Pseudomonas pelvic osteomyelitis in a healthy child. Infect Dis Rep 2011;4(1):e1.

10. Pineda C, Vargas A, Rodríguez AV.Imaging of osteomyelitis: current concepts. Infect Dis Clin North Am 2006;20(4):789-825. 